\title{
A Convenient Reduction of $\alpha$-Amino Acids to 1,2-Amino Alcohols With Retention of Optical Purity
}

\author{
Sun-Hee Hwang ${ }^{\dagger}$, Mark A. Blaskovich* and Hwa-Ok Kim ${ }^{\#}$
}

Molecumetics Ltd., $2023120^{\text {th }}$ Ave. NE., Bellevue, WA, 98005-2199, USA

\begin{abstract}
A convenient one-pot synthesis of 1,2-amino alcohols from $\alpha$-amino acids with retention of optical purity by use of 1,1'-carbonyldiimidazole and sodium borohydride is described.
\end{abstract}

Keywords: Amino acid, 1,2-amino alcohol, carbonyl diimidazole, sodium borohydride, acid reduction.

\section{INTRODUCTION}

The conversion of $\alpha$-amino acids into 1,2-amino alcohols provides access to a pool of useful chiral intermediates. Numerous methods have been developed for the reduction of unprotected $[1-10]^{1}$ or $N$-protected $[4,5,11-24]^{2} \alpha$-amino acids to the corresponding amino alcohols, including procedures in which the acid group is activated by conversion to a mixed anhydride [11-15], acid fluoride [18] or active ester [16,20-23], followed by reduction with sodium borohydride. We required a number of amino alcohols as intermediates for peptidomimetic synthesis, but found the standard mixed anhydride method to be capricious in our hands. Other methods required reagents that are difficult to handle, hazardous and/or expensive. We envisioned that modification of the activation step by employing 1,1'-carbonyldiimidazole (CDI) as the activation reagent would provide a convenient and inexpensive route to the desired product (see Fig. 1). The use of CDI is well known for the formation of esters [25], amides [26-28], and C-C bonds [29-31] via an imidazolide amide intermediate. However, reduction of the imidazolide amide to afford 1,2-amino alcohols [24] has not been thoroughly studied.

\section{RESULTS AND DISCUSSION}

Evaluation of a number of reaction conditions led to a convenient one-pot reaction sequence consisting of CDI activation of the $N$-protected amino acid in THF for 10 minutes

\footnotetext{
*Address correspondence to this author at Mimetica Pty. Limited, Institute for Molecular Bioscience, University of Queensland, 306 Carmody Road, St. Lucia, QLD 4072, Australia; Tel: 61-7-33462981; Fax: 61-7-3346-2998; E-mail: m.blaskovich@mimetica.com.au

${ }^{\dagger}$ Korea Institute of Science and TechnologyInformation, 66 Hoegiro, Dongdaemoon-gu, Seoul 130-741, Korea; E-mail:shhwang221 @ hotmail.com

"CreaGen Biosciences, Inc., 23 Rainin Road, Woburn, MA 01801, USA; E-mail:Kim@creagenbio.com

${ }^{1}$ Reduction reagents employed in the references for unactivated amino acids are as follows: [1] $\mathrm{BF}_{3} . \mathrm{OEt}, \mathrm{BH}_{3} . \mathrm{SMe}_{2}$; [2] $\mathrm{LiBH}_{4} / \mathrm{TMSCl}$; [3] $\mathrm{BF}_{3} . \mathrm{OEt}, \mathrm{BH}_{3} . \mathrm{SMe}_{2}$; [4] $\mathrm{NaBH}_{4}-\mathrm{H}_{2} \mathrm{SO}_{4} ;$ [5] $\mathrm{NaBH}_{4}-\mathrm{I}_{2} ;[6] \mathrm{Zn}\left(\mathrm{BH}_{4}\right)_{2} ;$ [7] $\mathrm{NaBH}_{4} / \mathrm{LiCl} /$ Amberlyst 15 ; [8] $\mathrm{LiBH}_{4} / \mathrm{TMSCl}$; [9] $\mathrm{BEt}_{3}, \mathrm{BH}_{3}$.THF; [10] $\mathrm{Zr}\left(\mathrm{BH}_{4}\right)_{4}$;

${ }^{2}$ Activation and reduction reagents employed in the references are as follows: [11] EtOCOCl/NMM, NaBH 4 ; [12] iBuOCOCl/NMM, NaBH $;$; [13] EtOCOCl/Et 3 N, $\mathrm{NaBH}_{4} ;[14] \mathrm{iBuOCOCCl} / \mathrm{Et}_{3} \mathrm{~N}, \mathrm{NaBH}_{4} ;[15] \mathrm{iBuOCOCCl} / \mathrm{Et}_{3} \mathrm{~N}, \mathrm{NaBH}_{4} ;[16] \mathrm{DCC} / \mathrm{N}-$ Hydroxysuccinimide, $\mathrm{NaBH}_{4} ;\left[\right.$ [17] $\mathrm{TiBH}_{4}(\mathrm{OiPr})_{2} ;\left[\right.$ [18] cyanuric fluoride, $\mathrm{NaBH}_{4} ;[19]$ 2-Cl-4,6-(MeO) $)_{2}-[1,3,5]$ triazine/NMM, $\mathrm{H}_{2}-\mathrm{Pd} / \mathrm{C} ;$ [20] BOP/DIPEA, NaBH $\mathrm{N}_{4} ;$ [21] DCC, $\mathrm{LiBH}_{4} ; \quad[22]$ DCC/N-Hydroxysuccinimide, $\mathrm{NaBH}_{4} ; \quad[23]$ DCC/NHydroxysuccinimide, $\mathrm{NaBH}_{4}$; [24] CDI, $\mathrm{NaBH}_{4}$.
}

at room temperature, followed by addition of a solution of sodium borohydride in water at $0^{\circ} \mathrm{C}$. The solution was acidified after 30 minutes and extracted with ethyl acetate. Product of sufficient purity ( $>95 \%$ by HPLC) for further reaction was obtained by simply passing the dried ethyl acetate extracts over a pad of silica gel, followed by solvent removal.

The CDI activation / sodium borohydride reduction procedure was applied to a variety of $\alpha$-amino acids as shown in Table 1. All of the substrates studied provided good to excellent chemical yields of the amino alcohol products. Several additional types of acid substrates were also successfully reduced to the alcohols 3-6 (see Fig. 2), including amino acid substrates attached to a solid support via their amino group, and a diacid monomethyl ester. For all products, LC-MS analysis showed the correct mass with $>95 \%$ purity. ${ }^{1} \mathrm{H}$ NMR spectra were in good agreement with the spectra of commercially available samples (when available).<smiles>[R]C(Nc1ccccc1)C(=O)n1ccnc1</smiles><smiles>[R]C(CO)NP</smiles>

Fig. (1). Reduction of $\alpha$-amino acids via CDI activation.

We considered it critical to establish that no racemization was occurring during the reduction sequence, especially as this parameter is often not assessed in other literature procedures. Comparison of optical rotation values with literature values can be unreliable, as trace impurities present in the unpurified products can affect the measured values. Instead, we analyzed a number of the enantiomeric sets of crude products on a chiral HPLC column (see Fig. 3 for 2 examples; the enantiomeric pairs derived from $\mathrm{L}-$ and $\mathrm{D}-\mathrm{Val}$, Nva, -Nle and -Cha were also examined). The amino alcohols all possessed $>99 \%$ ee with one exception, the alcohol 
Table 1. Yields of Amino Alcohols from $\alpha$-Amino Acids

\begin{tabular}{|c|c|c|c|}
\hline Amino Acid & Amino Alcohol Yield (\%) & Amino Acid & Amino Alcohol Yield (\%) \\
\hline Fmoc-L-Val-OH & 94 & Fmoc-D-Cha-OH & $>95$ \\
\hline Fmoc-D-Val-OH & 91 & Fmoc-L-Phe-OH & $>95$ \\
\hline Fmoc-L-Nva-OH & 99 & Fmoc-L-homoPhe-OH & 93 \\
\hline Fmoc-D-Ile-OH & $>98$ & Fmoc-D-Lys(Boc)-OH & 91 \\
\hline Fmoc-D-Leu-OH & 100 & Boc-L-Lys(Fmoc)-OH & 91 \\
\hline Fmoc-L-Nle-OH & 99 & Fmoc-L-Orn(Boc)-OH & 90 \\
\hline Fmoc-D-Nle-OH & 96 & Boc-L-Dap(Fmoc)-OH & 93 \\
\hline Fmoc-L-Chg-OH & 96 & Fmoc-L-Pro-OH & 61 \\
\hline Fmoc-D-Chg-OH & 97 & - & - \\
\hline
\end{tabular}

derived from Fmoc-D-Lys(Boc) (>97.8\% ee). Analysis of the latter crude compound was complicated by the presence of impurities near the retention time of the minor enantiomer (see Fig. 3f).

In summary, we have developed an efficient and mild one-pot synthetic method for the rapid preparation of 1,2amino alcohols from $\alpha$-amino acids with excellent yields. The key features of the procedure are the short reaction time, easy work up, lack of racemization, and compatibility with a variety of amino and ester protecting groups. The reaction is amenable to large-scale conversions (up to $10 \mathrm{~g}$ in our hands) as the reagents involved are easy to handle and relatively non-hazardous.<smiles>CC(C)N1CCC(CO)CC1</smiles>

3 $>95 \%$ yield<smiles>COC(=O)c1ccc(CO)cc1</smiles>

$>95 \%$ yield<smiles>OCc1ccc(CNC(F)F)cc1</smiles>

4

$>95 \%$ yield

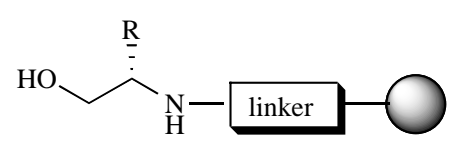

6

$>80 \%$ purity after cleavage
Fig. (2). Additional alcohol products obtained by acid reduction.

\section{EXPERIMENTAL SECTION}

The typical reaction procedure is as follows: To a stirred solution of Fmoc-L-Lys(Boc)-OH (1.4 g, $3 \mathrm{mmol})$ in THF $(10 \mathrm{~mL})$ was added CDI $(650 \mathrm{mg}, 4 \mathrm{mmol})$ at $\mathrm{rt}$. After 10
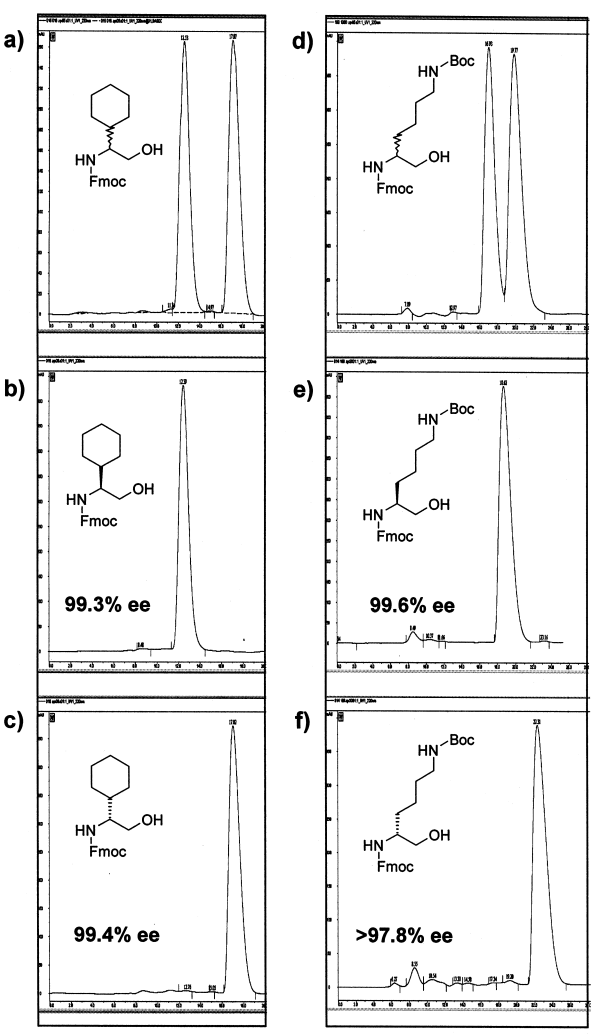

Fig. (3). Analysis of optical purity of 1,2-amino alcohol crude products ( $25 \mathrm{~cm}$ ChiracelODR column, $0.5 \mathrm{ml} / \mathrm{min}$ ).

a) 1:1 mixture of crude Fmoc-L- and -D-cyclohexylglycinol. b) crude Fmoc-L-cyclohexylglycinol. c) crude Fmoc-Dcyclohexylglycinol. d) 1:1 mixture of crude $N^{\alpha}$-Fmoc, $N^{\varepsilon}$-Boc-Land -D-lysinol. e) crude $N^{\alpha}$-Fmoc, $N^{\varepsilon}$-Boc-L-lysinol. f) crude $N^{\alpha}$ Fmoc, $N^{\varepsilon}$-Boc-D-lysinol. 
min, the solution was cooled to $0{ }^{\circ} \mathrm{C}$ and a solution of $\mathrm{NaBH}_{4}$ (190 mg, $5 \mathrm{mmol})$ in $\mathrm{H}_{2} \mathrm{O}(5 \mathrm{~mL})$ was added in one portion. The solution was then stirred for $30 \mathrm{~min}$. To this was added $1 \mathrm{~N} \mathrm{HCl}(50 \mathrm{~mL})$ and the solution was extracted with EtOAc $(2 \times 200 \mathrm{~mL})$. The combined extracts were washed with sat. $\mathrm{NaHCO}_{3}(50 \mathrm{~mL})$, brine $(50 \mathrm{~mL})$, dried $\left(\mathrm{MgSO}_{4}\right)$, and passed through a short pad of silica gel to provide a white solid (1.20 g, $88 \%)$. MS; $\mathrm{ES}^{+} \mathrm{m} / \mathrm{z} 455\left(\mathrm{M}+\mathrm{H}^{+}\right)$.

\section{ACKNOWLEDGEMENTS}

The authors thank Ken Farber for chiral HPLC analyses.

\section{ABBREVIATIONS}

\begin{tabular}{|c|c|c|}
\hline Ala & $=$ & alanine \\
\hline Asp & $=$ & aspartic acid \\
\hline CDI & $=$ & 1,1' -carbonyldiimidazole \\
\hline Cha & $=$ & cyclohexylalanine \\
\hline Chg & $=$ & cyclohexylglycine \\
\hline Dap & $=$ & 1,3-diaminopropionic acid \\
\hline Glu & $=$ & glutamic acid \\
\hline homoLeu & $=$ & homoleucine \\
\hline homoPhe & $=$ & homophenylalanine \\
\hline Ile & $=$ & isoleucine \\
\hline Leu & $=$ & leucine \\
\hline Lys & $=$ & lysine \\
\hline Nle & $=$ & norleucine \\
\hline $3 '-\mathrm{NO}_{2}-\mathrm{Tyr}$ & $=$ & ortho-nitrotyrosine \\
\hline Orn & $=$ & ornithine \\
\hline Pro & $=$ & proline \\
\hline Tle & $=$ & tert-butylleucine \\
\hline Val & $=$ & valine \\
\hline
\end{tabular}

\section{REFERENCES}

[1] Pridgen, L.N.; Prol Jr., J.; Alexander, B.; Gillyard, L. J. Org. Chem., 1989, 54, 3231.

[2] Giannis, A.; Sandhoff, K. Angew. Chem. Int. Ed. Engl., 1989, 28 , 218.

[3] Gage, J.R.; Evans, D.A. Org. Synth., 1989, 68, 77.

[4] Abiko, A.; Masamune, S. Tetrahedron Lett., 1992, 33, 5517.

[5] McKennon, M.J.; Meyers, A.I.; Drauz, K.; Schwarm, M. J. Org. Chem., 1993, 58, 3568.

[6] Narasimhan, S.; Madhavan, S.; Prasad, K.G. Synth. Commun., 1996, 26, 703 .

[7] Anand, R.C.; Vimal Tetrahedron Lett., 1998, 39, 917.

[8] Quagliato, D.A.; Andrae, P.M.; Matelan, E.M. J. Org. Chem., 2000, 65, 5037.

[9] García, M.; Serra, A.; Rubiralta, M.; Diez, A.; Segarra, V.; Lozoya, E.; Ryder, H.; Palacios, J.M. Tetrahedron: Asymm., 2000, 11, 991.

[10] Narasimhan, S.; Balakumar, R. Synth. Commun., 2000, 30, 4387.

[11] Kokotos, G. Synthesis, 1990, 299.

[12] Rodriguez, M.; Llinares, M.; Doulut, S.; Heitz, A.; Martinez, J. Tetrahedron Lett., 1991, 32, 923.

[13] Moree, W.; Van der Marel, G. A.; Liskamp, R. M. J. Tetrahedron Lett., 1992, 33, 6389.

[14] Ho, M.; Chung, J. K. K.; Tang, N. Tetrahedron Lett., 1993, 34, 6513.

[15] Wei, Z. -Y.; Knaus, E. E. J. Org. Chem., 1993, 58, 1586.

[16] Ouerfelli, O.; Ishida, M.; Shinozaki, H.; Nakanishi, K. Ohfune, Y. Synlett, 1993, 409 .

[17] Ravikumar, K.S.; Chandrasekaran, S. J. Org. Chem., 1996, 61, 826

[18] Kokotos, G.; Noula, C. J. Org. Chem., 1996, 61, 6994.

[19] Falorni, M.; Giacomelli, G.; Procheddu, A.; Taddei, M. J. Org. Chem., 1999, 64, 8962.

[20] McGeary, R. P. Tetrahedron Lett., 1998, 39, 3319.

[21] Herbert, J. M.; Hewson, A. T.; Peace, J. E. Synth. Commun., 1998 28,823 .

[22] Falorni, M.; Porcheddu, A.; Taddei, M. Tetrahedron Lett., 1999, 40, 4395 .

[23] Feng, X.; Edstrom, E.D. Tetrahedron: Asymm., 1999, 10, 99.

[24] Kim, H.-O.; Kahn, M. Synlett, 1999, 1239.

[25] Saha, A. K.; Schultz, P.; Rapoport, H. J. Am. Chem. Soc., 1989, $111,4856$.

[26] Skiles, J. W.; Fuchs, V.; Leonard, S. F. Bioorg. Med. Chem. Lett., $1991,1,69$.

[27] Mickelsonm J. W.; Jacobson, E. J. Tetrahedron Asymm., 1995, 6, 19.

[28] Kim, H. -O.; Kahn, M. Synlett, 1995, 549.

[29] Gomez,-Monterry, I.; Gonzalez-Muniz, R.; Herranz, R.; GraciaLopez, M. T. Tetrahedron Lett., 1993, 34, 3593.

[30] Schuda, P. F.; Greenlee, W. J.; Chakravarty, P. K.; Eskola, P. J. Org. Chem., 1988, 53, 873.

[31] Harris, B. D.; Bhat, K. L.; Joullie, M. M. Tetrahedron Lett., 1987, $26,2837$.

Received: August 29, 2008

() Hwang et al.; Licensee Bentham Open.

This is an open access article licensed under the terms of the Creative Commons Attribution Non-Commercial License (http://creativecommons.org/licenses/by-nc/3.0/) which permits unrestricted, non-commercial use, distribution and reproduction in any medium, provided the work is properly cited. 